\title{
La delincuencia empresarial y la responsabilidad penal del socio
}

\author{
JORGE ARTURO ABELLO GUAL \\ Fecha de recepción: 26-06-2009 - Aprobación: 21-07-2009
}

\section{INTRODUCCIÓN}

La delincuencia empresarial se define en este trabajo como aquella que utiliza las estructuras societarias para realizar delitos, que pueden ser de diversa índole, pues las sociedades se constituyen en "fachadas" o en medios para ocultar y consumar actos delictivos.

Esta nueva forma de delincuencia ha creado una serie de inconvenientes a las autoridades judiciales, que parecen no estar habituadas a combatir este nuevo tipo de crimen, realizado desde una entidad que, inicialmente, se constituye de manera legal, ejecuta actividades legales y se las arregla para borrar cualquier indicio de los actos ilícitos que realiza bajo una fachada.

Las modalidades de este tipo de delincuencia son tan variadas, que las clasificaciones no son suficientes; por tanto, se citan algunas de las situaciones que configuran la delincuencia empresarial, para que el lector pueda ubicarse mejor en la materia.

\section{Abstract}

This study describes some ways of business crime in order to make the reader aware of the importance the legal protection has in business activities, where crime organizations are also developed in a parallel way. These take advantage of the social structure in order to escape from the legal search and make the research of their behavior difficult. At the same time, there is also a study of the criteria designed by the doctrine in order to give legal responsibility to the partners and directors of the companies.

\section{Key words}

Legal responsibility, company, partners, administrators, author of the crime, and participation.

Responsabilidad penal, empresa, socios, administradores, autoría y participación. 


\section{Aspectos político-criminales de la delin- cuencia empresarial}

Para comenzar, se hace referencia a aquellas actividades ilícitas que utilizan las sociedades como instrumento para llevarse a cabo. Así, por ejemplo, pueden presentarse algunas de las siguientes situaciones.

Puede ocurrir que las sociedades sean utilizadas para administrar los dineros provenientes de actividades ilícitas; se configura entonces el delito de lavado de activos. También puede pasar que la empresa misma financie las actividades ilícitas que revierten en su propio beneficio. En otras ocasiones sucede que la sociedad en ejercicio de su objeto social decide realizar un ilícito, porque financieramente le es rentable su realización, como puede ser el caso de un delito ambiental (Tiedemann, 2007) o de un delito contra la libertad de asociación. En muchas ocasiones este tipo de acciones son realizadas esporádicamente, pero en otros se convierten en una política institucional.

Esta última posibilidad descrita debe diferenciarse de otra modalidad común que se presenta cuando se crea una sociedad solamente para realizar actividades ilícitas. En tal evento, la sociedad se constituye como "un antifaz" para darle apariencia de legalidad a las actividades empresariales que desarrolla, en tanto va transmitiendo confianza al público, pero después de determinado tiempo se destapa la gran estafa, y los socios y trabajadores desaparecen sin dejar rastro alguno, luego de conseguir un provecho ilícito de sus clientes, o más bien de sus víctimas.

Otramodalidaddedelincuenciaempresarialesaquellaque se presenta dentro de la misma organización societaria, cuando en el normal desarrollo del objeto social se realiza una fraudulenta administración de los negocios sociales, por parte de ciertos socios o del personal directivo, que aprovechándose de sus prerrogativas y de la confianza que se le ha encomendado, ejecutan ciertos actos riesgosos, sin informar previamente a los demás socios o a sus superiores, y que, como consecuencia, le producen grandes pérdidas a la sociedad conduciéndola, incluso, a la quiebra. Para prevenir todos estos tipos de conductas, el Código penal español tiene un capítulo denominado delitos societarios (Seminara, 2004; Martínez Buján, 2004), que busca proteger a la sociedad de las acciones fraudulentas que realicen los directivos y asociados y le puedan ocasionar un perjuicio irreparable a otros socios y a todas las demás relacionadas con la compañía.
También existe otro tipo de delitos que se cometen por medio de sociedades mercantiles, cuando se presentan conductas que buscan evadir obligaciones tributarias (Tiedemann, 2007) o contractuales (Canestrari, 2004; González, 2004). Esta modalidad se da cuando los socios evitan el cumplimiento de sus obligaciones mediante el alzamiento de bienes o la simulación de una liquidación obligatoria de su sociedad. Tales maniobras fraudulentas se producen necesariamente con la presentación de documentos falsos que alteran, suprimen o modifican los estados contables de la empresa, con el fin de conseguir mayores plazos o mejores condiciones de parte de sus acreedores para el pago de sus deudas.

Por último, se reseñan dos clases más de delincuencia empresarial que son muy recurrentes en la actualidad y que se dan en el ámbito de la competencia, en la carrera por acaparar todo un mercado con un producto. La primera se presenta cuando, en el plano de la competencia empresarial, una sociedad decide disminuir sus costos omitiendo ciertas exigencias de seguridad del producto que está elaborando. Piénsese, por ejemplo, en aquellos casos en los que no se hace un efectivo control de calidad a un producto y se fabrica un lote con un defecto grave para la seguridad de los consumidores, como puede ser la producción de una serie de vehículos que tengan un problema en el diseño de estabilidad o un problema en los frenos, que hace que el automóvil tienda a volcarse cuando excede de ochenta kilómetros por hora; o en un alimento que por falta de un conservante se descompone antes de la fecha estipulada y es injerido por un consumidor que muere por intoxicación. Estos casos, realmente delicados, no solamente tienen unas repercusiones patrimoniales en la indemnización de perjuicios, sino que a su vez tienen unos efectos penales, toda vez que producen resultados previstos como delitos ${ }^{1}$.

El segundo tipo se produce en la competencia por la sobrevivencia empresarial, cuando los socios de

\section{JORGE ARTURO ABELLO GUAL}

Abogado y especialista en Derecho penal de la Universidad del Norte, candidato a magíster de la Universidad de los Andes. Profesor de tiempo completo e investigador del Politécnico Grancolombiano.

jabellog@poligran.edu.co

1 Recuérdese el caso del aceite de colza, en España, fallado por el Tribunal Supremo en su Sentencia del 23 de abril de 1992. 
una compañía están dispuestos a realizar cualquier tipo de actividades con el objeto de doblegar a su competencia. Dichas acciones pueden ir desde actos de competencia desleal hasta verdaderos delitos como la extorsión, el hurto e, inclusive, el homicidio. Las empresas son evidentemente grupos económicos que manejan muchos recursos, y no cabe duda de que algunas personas, para mantener un estatus socioeconómico, inducen y organizan actos delictivos que desplacen y debiliten a sus competidores. Esta modalidad permite hacer un símil con las mafias del licor o de las drogas, cuyos jefes prefieren doblegar a la fuerza a su competencia para efectos de mantener la hegemonía y el monopolio de la actividad ilícita.

Vistos algunos casos de delincuencia empresarial, ahora se analizan algunos criterios que permiten la imputación de responsabilidades a los socios o el personal directivo.

\section{Estudio preliminar sobre la autoría y participación en la delincuencia empre- sarial}

Los delitos que se perpetran en o mediante sociedades crean un verdadero reto para el Derecho penal, pues el principio de responsabilidad personal surge como un derecho que evita que las autoridades judiciales imputen responsabilidad a todos los miembros de una sociedad mercantil involucrada en una investigación penal.

De conformidad con el principio de la responsabilidad personal, cada sujeto responde por su grado de participación en los hechos y según su nivel de culpabilidad en los mismos, acorde, a su vez, con la prohibición de la aplicación de la responsabilidad objetiva en el ámbito penal, que señala que la mera causalidad no es suficiente para la imputación de una conducta punible.

Por esta razón, cuando una autoridad pública tiene serios indicios de que en una sociedad mercantil se están realizando actividades ilícitas, debe realizar una investigación previa para lograr determinar la estructura, las funciones y los miembros de los órganos de la sociedad mercantil en la que se produjo un delito, si es que pretende llevar a juicio a alguna persona natural por los hechos delictivos. En desarrollo de esta investigación debe establecer, por lo menos, las siguientes pruebas:

a. De conformidad con la ley y los estatutos, cuáles son los órganos directivos, los órganos encarga-

2 Sobre este punto, véase Velásquez, 2007. dos de la administración general, los órganos que ejecutan las directrices y los órganos de control y vigilancia internos.

b. Cuáles son las funciones asignadas a cada órgano en la ley y en los estatutos.

c. Qué personas conforman dichos órganos.

Una vez culminada esa etapa, debe iniciar el análisis jurídico sobre la posible participación de cada miembro en la comisión de una conducta punible, y debe hacerlo de conformidad con los criterios de imputación que rigen la autoría y la participación presentes en el Derecho penal.

De acuerdo con el Código penal, cp, (artículo 29), son autores los que realizan la conducta punible o utilizan a otro como instrumento. A continuación, el mismo artículo menciona que son coautores los que, mediando acuerdo común, actúan con división del trabajo criminal, atendiendo la importancia del aporte $^{2}$. Por último, establece que también es autor quien actúa como miembro u órgano de representación autorizado o de hecho de una persona jurídica, de un ente colectivo sin tal atributo o de una persona natural cuya representación voluntaria se detente, y realiza la conducta punible, aunque los elementos especiales que fundamentan la penalidad de la figura punible respectiva no concurran en él, pero sí en la persona o ente colectivo representado.

Lo primero, es establecer que para que exista autor se requiere que la persona a quien se le esté imputando bajo ese título tenga el dominio del hecho, lo que significa que un sujeto debe tener el poder para adelantar, suspender o aplazar la conducta punible que ha iniciado (Velásquez, 2007). Ese dominio del hecho es el criterio que permite diferenciar un autor de un partícipe, en los casos difíciles en los que concurren varias personas en la realización de la conducta.

Así, entonces, como dice el Código penal, hay coautoría cuando existe un acuerdo común y división de trabajo. Solo existe un elemento que permite diferenciar un autor de un cómplice, y es la entidad del aporte, pues es de acuerdo con la importancia en el aporte que se puede argumentar si una persona es coautora o partícipe (Velásquez, 2007). Según el artículo 30 del estatuto penal, el cómplice es "quién contribuye a la realización de la conducta antijurídica o preste una ayuda posterior, por concierto previo o concomitante a la misma". De conformidad con esta definición, es necesario que 
exista una contribución a la realización de una conducta punible y un acuerdo previo o concomitante, que son elementos comunes con la coautoría. Sin embargo, la división de trabajo y la entidad del aporte producen unos tamices que logran una diferenciación, pues cuando se dice que hay división de trabajo, existe una contribución al hecho, pero implica repartición de tareas en un acto que se realiza de forma grupal (Velásquez, 2007); por tanto, la diferencia entre coautor y partícipe queda enmarcada en la discusión sobre la importancia o la relevancia del aporte, quedando así establecido que en cada caso concreto debe analizarse que, si el aporte es importante, el individuo debe ser considerado como un coautor, pero si el aporte es tangencial, como un cómplice.

La Corte Suprema de Justicia ha señalado sobre la materia:

(...) son aquellos autores materiales o intelectuales que conjuntamente realizan un mismo hecho punible, ya sea porque cada uno de ellos ejecuta simultáneamente con los otros o con inmediata sucesividad idéntica conducta típica, ora porque realizan una misma y compleja operación delictiva con división de trabajo, de tal manera que cada uno de ellos ejecuta una parte diversa de la empresa común (Corte Suprema de Justicia, 24 de abril de 2003).

En otra decisión, la misma Corte también explicó que se puede presentar coautoría impropia,

(...) cuando una conducta punible es realizada en forma comunitaria y con división de trabajo por varias personas que la sumen como propia, aunque la intervención de cada una de ellas tomada en forma separada no ejecute en forma total el supuesto de hecho contenido en el respectivo tipo penal (Corte Suprema de Justicia, 6 de agosto de 2003).

En esta discusión se habla mucho de la teoría del dominio funcional, en los casos de autoría, y se establece que el dominio sobre el hecho se convierte en un codominio del hecho o dominio funcional, cuando todas las personas que intervienen en el delito controlan el resultado, pues su ocurrencia depende de los aportes de cada persona de acuerdo con la división de trabajo (Tribunal Superior de España, 11 de agosto de 2000). En conclusión, es autor solo aquel que ostenta el dominio funcional; quién carece de él es un participe.
El tema es relevante en los delitos realizados en o mediante sociedades mercantiles, toda vez que en estos casos la participación plural de personas es, prácticamente, necesaria, pues se está hablando de una agrupación de personas que actúan conjuntamente para desarrollar un objeto social inicialmente lícito.

La participación conjunta de personas genera una verdadera problemática, como se planteó al inicio de este escrito, puesto que no puede imputársele la misma responsabilidad a todas las personas que actúan en la sociedad, porque en el Derecho penal están prohibidas las presunciones de culpabilidad, por la aplicación de los principios de presunción de inocencia y responsabilidad personal (Faraldo, 1996).

Así entonces, en cada caso en concreto el investigador debe encontrar pruebas suficientes para lograr imputar responsabilidad a cada persona, de acuerdo con las funciones que le han sido asignadas en la ley y en los estatutos de la sociedad. En todo caso, las imputaciones se pueden hacer tanto por acción como por omisión de esas funciones.

Pero el tema sigue siendo complicado, toda vez que en las estructuras societarias muchas veces se toman decisiones que aparentemente son lícitas, pero que tienen unos resultados con consecuencias penales, y que no todos los que deciden pueden ser conscientes de la ilicitud. Y esas son, sin duda, las primeras personas que hay que exonerar de la responsabilidad penal, pues ellas se encuentran actuando de buena fe y solo son utilizadas como instrumentos para realizar el ilícito de otro sujeto. Estas personas que actúan por error o mediante engaño no son sancionadas en el Derecho penal (Velásquez, 2007). Pero, en cambio, sí se responsabiliza al sujeto que está detrás; es decir, a la persona que se aprovechó de la situación para realizar su delito por medio de otra. El problema es que en muchas ocasiones esas personas que están detrás no son ni siquiera integrantes de la sociedad que se investiga y, por tanto, son más difíciles de buscar y de identificar (Faraldo, 1996).

\section{Responsabilidad de los socios en las decisiones empresariales}

En una sociedad se encuentran, por una parte, las personas que participan en la toma de decisiones en una sociedad, por otra, las que ejecutan los actos y, también, las que se encuentran encargadas del control y la vigilancia. 
Los encargados de tomar las principales decisiones directivas son los socios, responsables de las decisiones y directrices que tomen en asamblea los asociados o accionistas, pero de forma muy especial, ya que en todas ellas se sigue una regla general en la imputación de responsabilidad por la toma de decisiones, que es la siguiente: "quién no se oponga a una decisión ilícita, y además no haga nada para corregirla, será responsable por los resultados que se produzcan en desarrollo de esa decisión” (Faraldo, 1996).

En consecuencia, para que un socio pueda salvar su responsabilidad por la toma de una decisión ilícita debe oponerse a la misma y, a su vez, realizar todos los actos tendientes para dejarla sin efecto. De esta forma, se configura una responsabilidad de acción, cuando aprueba una decisión que es ilegal, y una responsabilidad por omisión, en caso de que no realice las acciones tendientes a dejar la decisión sin efectos (Faraldo, 1996).

Esta última obligación hace que los socios ausentes en una asamblea general sean responsables si omiten realizar las acciones pertinentes para dejar sin efectos la decisión ilegal, después de conocerla (Faraldo, 1996), puesto que se entiende como un asentimiento o colaboración de la ilegalidad.

En igual sentido, se opera en la responsabilidad de los miembros de la junta directiva, cuando en sus reuniones se adopten medidas administrativas ilegales.

\section{Aspectos complejos de la imputación penal}

Para continuar con el tema de la autoría y la participación en los delitos societarios, se tratan enseguida varios temas relacionados con las figuras de la imputación jurídica que deben utilizarse para establecer la responsabilidad penal de los socios y de los directivos.

En el aparte anterior se desarrolló un criterio que viene utilizándose para imputar responsabilidad penal a los directivos en la toma de decisiones, según el cual, un socio es responsable por participar en una reunión en la que se tome una decisión que implica la realización de una conducta punible, cuando (a) votó a favor de la decisión, (b) no votó o (c) votó en contra pero no realizó ninguna acción tendiente a revocar la decisión (Faraldo, 1996). En esta sección se plantean otros criterios utilizados por la doctrina para imputar responsabilidad a los socios y directivos de una sociedad.

Una de las razones por las cuales se hacen necesarios los criterios de imputación en el Derecho penal es, precisamente, para evitar el problema de la responsabilidad objetiva, pues no por el solo hecho de ser socio, directivo o empleado de una sociedad se puede ser responsable penalmente por una conducta punible que se haya realizado en desarrollo del objeto social.

En esta perspectiva, se destaca, para comenzar, un aspecto decisivo en los criterios de imputación, que es el de la complicación que ha generado el principio de que las sociedades no delinquen, pues en virtud de ese criterio se promovió, en gran parte, la delincuencia por medio de sociedades, aunque, a su vez, se buscaron criterios jurídicos más eficaces y menos garantistas para evitar que tales hechos quedaran en la impunidad. Sucedió que los criterios que se utilizaban tradicionalmente para imputar responsabilidad penal resultaron insuficientes para tratar con la nueva criminalidad. Así, por ejemplo, la teoría del dominio del hecho dejó de ser eficiente en los asuntos de la delincuencia empresarial.

El problema de la teoría del dominio del hecho es que en los casos de los delitos realizados desde la sociedad, el autor material de un hecho punible es el de menor transcendencia. Considérese un trabajador que recibe la orden de su superior de adulterar unos estados financieros que serán presentados al día siguiente a la junta de accionistas. El empleado lo hace e incurre en una falsedad. ¿Se puede afirmar el autor principal del delito es el empleado? No. En los delitos empresariales, el papel que ejerce la persona que está detrás, y la de más atrás, es evidentemente más importante que el del autor material. De ello se deriva la facilidad en la impunidad en los delitos societarios, pues quien está detrás siempre está cubierto en la estructura societaria, o muchas veces ni siquiera pertenece a ella, todo lo cual dificulta su persecución por el Derecho penal (Faraldo, 1996).

Esta realidad crea un cambio de paradigma en el Derecho penal, pues el principio del acto establece, desde el punto de vista dogmático, que la pena del autor debe ser mayor que la de un partícipe (Velásquez, 2007), toda vez que es el primero quien realmente lesiona o coloca en riesgo efectivo el bien jurídico, y su acto merece mayor reproche que el de un partícipe. Siempre se ha dicho que sin autor no puede haber partícipe, ya que esta figura es accesoria de la primera. Así, por ejemplo, si alguien contrata a una persona para matar 
a otra, y el encargado del asesinato recibe el dinero, se va del país y no cumple el encargo, no podría haber instigación, puesto que el hecho no ha llegado siquiera al grado de tentativa.

Sin embargo, por razones político-criminales, hoy en día se han creado figuras para que, de conformidad con la realidad, la autoría se entienda más amplia y se apliquen otros criterios para imputar responsabilidad penal a personas que actúan en un hecho delictivo, aunque inicialmente no tengan el dominio del hecho, pero que de conformidad con otros criterios de imputación, como la posición de garante, la teoría de los roles, la teoría de la autoría mediata por dominio de la organización, los delitos de omisión de deber y los delitos de dominio por competencia, se les puede atribuir responsabilidad penal en la realización de una conducta, a título de autor ${ }^{3}$.

La importancia del sujeto que está detrás, desde el punto de vista político-criminal, es enorme. Basta con recordar los casos de los grandes capos de la droga en la historia de Colombia, como Pablo Escobar y Gonzalo Rodríguez Gacha, o los de la guerrilla de Tirofijo y el Mono Jojoy, o también los de los paramilitares de Carlos Castaño y Mancuso. En todos estos casos de narcotráfico, la importancia del autor material de un hecho punible ordenado por ellos se pierde, pues se puede decir que en estos eventos existen ya criminales de escritorio que solo dan órdenes.

Ello hizo posible, por ejemplo, que en Colombia el Código penal estableciera la misma pena para el autor y para el instigador: "Quien determine a otro a realizar la conducta antijurídica incurrirá en la pena prevista para la infracción" (artículo 30 del cP), precepto legal que, como se dijo ya, vulnera el principio del acto, que propende porque la pena del autor sea mayor que la del partícipe (Velásquez, 2007).

En el caso de los delitos realizados desde las empresas, sin duda el sujeto que está detrás siempre va a tener mayor importancia que la del autor material del hecho punible, por razones político-criminales; es decir, el hecho de que procesen al administrador o al empleado de una empresa no evita que quien está detrás se favorezca impunemente de la conducta punible realizada, ni tampoco evita que la conducta no se vuelva a cometer, pues, como dijo la Corte Constitucional, en las sentencias C-843 de 1999 y C-558 de 2004, muchas veces la comisión de un delito hace parte del presupuesto empresarial, y así se aprese al autor material, la empresa sigue favoreciéndose desde el punto de vista económico.

Por estas razones, se han comenzado a variar, y sobre todo a flexibilizar, los criterios de imputación, para evitar la impunidad de las personas que están detrás de los autores materiales. Así, por ejemplo, la Corte Suprema de Justicia (sentencia del 23 de noviembre de 2003) maneja el criterio de la coautoría impropia, según el cual, para que exista coautoría no se requiere que todas las personas que intervienen en el hecho punible deban realizar el verbo rector, sino que se requiere, principalmente, que exista una división de trabajo, en la cual el aporte de cada persona es indispensable para la realización de la conducta punible. De acuerdo con esta teoría, ya la realización material del hecho punible no se hace el centro de la acción, sino el dominio funcional sobre el mismo; es decir, que la consumación de una conducta se deba a la realización de la labor de conformidad con el plan criminal (Berruezo, 2007). Este criterio, aunque abre el espectro de posibilidades para la punición del Derecho penal, aún está limitado por el aporte indispensable para la realización del hecho punible.

Sin embargo, se debe mencionar que hay otros criterios que definitivamente no parecen tener los límites muy definidos, como la teoría de los delitos de dominio por la competencia (García, 2006 y Berruezo, 2007). Una persona tiene dominio de un hecho si tiene la competencia de poder disminuir los efectos adversos que puede causar una fuente de riesgos. Esto significa, en gran parte, que el solo hecho de que alguien constituya una sociedad para desarrollar una actividad empresarial ya está creando una fuente de riesgo para la comunidad y, por ello, debe mantener esa fuente de riesgo dentro de sus límites. De esta manera, el hecho de no realizar los actos necesarios para mantener esa fuente de riesgo dentro de los límites permitidos, posibilita imputarle responsabilidad al empresario (García, 2006 y Berruezo, 2007).

Sin embargo, para explicar de mejor forma este criterio, se incluyen la teoría de los roles (Jackob, 1996) y la posición de garante para establecer los alcances y límites del mismo. La teoría de los roles permite determinar dos tipos de papeles que desempeñan los individuos en una sociedad: el rol general y los roles especiales. El primero tiene que ver con el deber que le asiste a todo individuo de respetar los derechos de los demás para poder convivir en paz. Este rol permite prohibirle a cualquier ciudadano la realización de actividades que tengan como consecuencia previsible

3 Sobre el tema pueden consultarse García, 2006 y Berruezo, 2007. 
el daño de un derecho de otra persona. Por su parte, los roles especiales ya tienen que ver con las actividades específicas que se le encomiendan a un individuo para evitar que se vulneren ciertos derechos específicos, cuya protección se le ha encargado.

De esta forma, con los roles especiales se comienza a hablar de la posición de garante que tiene una persona cuando se le encomienda el cuidado de un bien jurídico o el control de una fuente de riesgo. Por tanto, la posición de garante de un individuo le exige que deba actuar para impedir un resultado típico. Es así como la sanción no se produce por haber realizado una conducta, sino por no haber actuado para evitar la vulneración de un bien jurídico que se encontraba bajo su custodia. No se está, entonces, frente a un delito de acción sino a un delito de omisión (artículo 25 del cP).

A partir de esa base teórica para imputar un hecho punible a título de autoría, se puede comenzar a divisar la aplicación de estos criterios a los socios de las compañías. El solo hecho de constituir una sociedad para el desarrollo de una actividad empresarial ya configura, en cabeza del socio, la posición de garante del correcto funcionamiento de la estructura societaria, con la obligación de evitar cualquier acto que tenga como resultado un delito (García, 2006; Berruezo, 2007), pero con el único límite de que la posición de garante solo se puede aplicar respecto de las actividades comprendidas en el objeto social de la compañía.

Esta postura definitivamente amplía el espectro de punición y, en términos generales, hace responsables a los socios por todos los resultados típicos producidos en desarrollo del objeto de su sociedad, no tanto por ejecutarlos materialmente, e inclusive no solamente por dar la orden de hacerlo, sino por no evitarlos (García, 2006). Este criterio cumple con la necesidad políticocriminal de prevenir la impunidad en las estructuras societarias, pero es excesiva, en la medida en que ataca una persona con una calidad específica (la de socio), y no por lo que realmente tuvo la capacidad de hacer. Así entonces, al socio se le podrá imputar la conducta punible porque su calidad de tal le permitía tener competencia para evitar el resultado punible.

Sobre esta materia es necesario precisar que cada caso en concreto debe examinarse para establecer si el socio tenía la capacidad de actuar, teniendo el deber de hacerlo, y no lo hizo (Gómez, 2003), pues nadie está obligado a lo imposible.
Cabe mencionarse que este tipo de imputación es más aplicable en las sociedades de tipo personal, donde los socios también ostentan la calidad de administradores. Por el contrario, no sería fácilmente aplicable a las sociedades en las que las facultades administrativas han sido delegadas a otros órganos, como por ejemplo una junta administradora. En tales eventos, la competencia sobre el hecho se pasa a esa junta, aunque los socios no dejan de tener responsabilidad por el control y vigilancia que deben realizar de los asuntos sociales. Se aplica de esta manera el principio de confianza como forma de limitar la responsabilidad penal.

El principio de confianza permite establecer responsabilidades a cada persona, según el rol desempeñado y de acuerdo con la división del trabajo (Reyes, 2005), según la diferenciación en el tipo de relación; es decir, si son relaciones de orden horizontal (cooperación), cada quien responde por sus obligaciones, pero si son relaciones de orden vertical (de subordinación), el superior es responsable por el control y supervisión del trabajo de su subordinado, sin perjuicio de la responsabilidad del superior en la escogencia del personal según experiencia y capacidad; por tanto, el nivel de control y supervisión que debe ejercer el superior sobre el trabajo del subalterno se aumenta o disminuye de acuerdo con la capacidad y experiencia de este último.

Así entonces, la responsabilidad de un socio sobre los actos de sus subalternos depende en gran medida de la demostración de diligencia en el control y vigilancia de los asuntos, pues la ampliación de la punibilidad por los criterios que ya se explicaron hace muy difícil la situación del empresario, dada su posición de garante.

\section{Discusión}

Por razones de espacio, desafortunadamente no se tratan otros temas referentes a los criterios de imputación a título de autoría y participación en la delincuencia empresarial; sin embargo, con este texto se logra introducir y explicar en parte la problemática que se viene presentando a la hora de levantar cargos en contra de los socios y directivos de las empresas.

En este trabajo se logran establecer varias modalidades de delincuencia empresarial, que sin duda se vienen incrementando por las condiciones competitivas del mercado, por la facilidad de ocultarse en las estructuras societarias y por las dificultades que les significan a las autoridades las investigaciones de este tipo de delitos. 
Se puede ver, de igual manera, la discusión que existe entre la utilización de los criterios tradicionales, como el dominio del hecho, y la utilización de las nuevas tendencias, como la posición de garante. Sobre la primera se menciona que es muy limitada, pues no tiene en cuenta las nuevas modalidades de la autoría que ha introducido la delincuencia empresarial; y sobre la segunda se menciona que es muy drástica, pues no tiene límites suficientes para evitar soluciones injustas.

Por último, este documento ofrece varios puntos para seguir trabajando más adelante, por la necesidad que genera el nuevo mundo de relacionarnos cada vez más con personas jurídicas en el desarrollo de nuestras actividades cotidianas.

\section{BIBLIOGRAFÍA}

Bacigalupo, E. (2005). Posición de garante en el ejercicio de funciones de vigilancia en el ámbito empresarial. Curso de Derecho Penal Económico (2. ${ }^{a}$ ed.). Madrid: Marcial Pons y Ediciones Jurídicas y Sociales.

Barata, A. (1998). Política criminal entre la política de seguridad y la política social en países con grandes conflictos. Memorias foro de política criminal. En Seminarios, 9. Pontificia Universidad Javeriana.

Berruezo, R. (2007). Responsabilidad penal en la estructura de la empresa. Montevideo y Buenos Aires: B de F Editorial.

Bustos Ramírez, J. (1987). Control social y sistema penal. Barcelona: Promoción Publicaciones Universitarias.

Canestrari, S. (2004). Riesgo empresarial e imputación subjetiva en el Derecho concursal. En J.M. Terradillos Basoco y M. Acale Sánchez (Eds.), Temas de Derecho Penal Económico. Madrid: Trotta: 67-82.

Corte Suprema de Justicia. (2003). Sentencia del 24 de abril. M.P. Álvaro Orlando Pérez Pinzón.

Corte Suprema de Justicia. (2003). Sentencia del 6 de agosto.

Corte Constitucional. (1999). Sentencia C-843.
Corte Constitucional. (2004). Sentencia C-554.

Faraldo Cabana, P. (1996). Delitos societarios. Valencia: Tirant lo Blanch.

Gómez Pavajeau, C.A. (2003). Estudios de dogmática en el nuevo Código Penal (Parte 1, $2^{\mathrm{a}}$ ed.). Bogotá: Ediciones Jurídicas Gustavo Ibáñez.

González Cusaac, J.L. (2004). Las insolvencias punibles. En J.M. Terradillos Basoco y M. Acale Sánchez (Eds.), Temas de Derecho Penal Económico. Madrid: Trotta: 83-114.

Jackobs, G. (1996). El concepto penal de acción. Bogotá: Universidad Externado de Colombia.

Martínez-Buján Pérez, C. (2004). Administración fraudulenta en sociedades de inversión. En J.M. Terradillos Basoco y M. Acale Sánchez (Eds.), Temas de Derecho Penal Económico. Madrid: Trotta: 35-66.

Newman, E. (2005). Los que viven del delito y los otros. La delincuencia como industria (3. ${ }^{\mathrm{a}}$ ed.). Bogotá: Temis.

Reyes Alvarado, Y. (2005). Imputación objetiva (3ª ed.). Bogotá: Temis.

Seminara, Sergio. (2004). El delito de la infidelidad en la gestión de los intermediarios financieros. Temas de Derecho Penal Económico. Madrid: Trotta: 17-34.

Tiedemann, K. (2007). Derecho Penal y nuevas formas de criminalidad. Lima: Grijley.

Tribunal Superior de España. (2000). Sentencia del 11 de agosto.

Velásquez Velásquez, F. (2007). Manual de Derecho Penal ( $3^{\mathrm{a}}$ ed.). Bogotá: Comlibros.

Zaffaroni, E.R. (2003a). Criminología (3ª reimpresión). Bogotá: Temis.

Zaffaroni, E.R. (2003b). Culpabilidad por vulnerabilidad. Macerata. Consultado en www.carlosparma.com.ar/zaffmacerata.htm. 